\title{
The Impact of Gender and Age on Cardiovascular Health in Germany
}

Friederike Kendel \& Monika Sieverding

\section{Introduction}

When women in Germany are asked what they regard to be their greatest personal health risk, over two-thirds report that breast cancer is the disease they fear the most. According to a survey conducted by a German health insurance fund, only $25 \%$ of women cite cardiovascular disease in this context (Deutsche Angestellten Krankenkasse DAK, 2002). However, according to information from the German Federal Statistical Office, a total of 17,173 women died in Germany from mammary carcinoma in the year 2003, compared to 29,550 women who died from acute myocardial infarction (Figure 1). Why is the risk of cardiovascular events so drastically underestimated by women themselves, as well as by those around them?

Figure 1: Mortality rates among women (per 100,000 population) for breast cancer and myocardial infarction according to age 2003 (StBa, 2005)

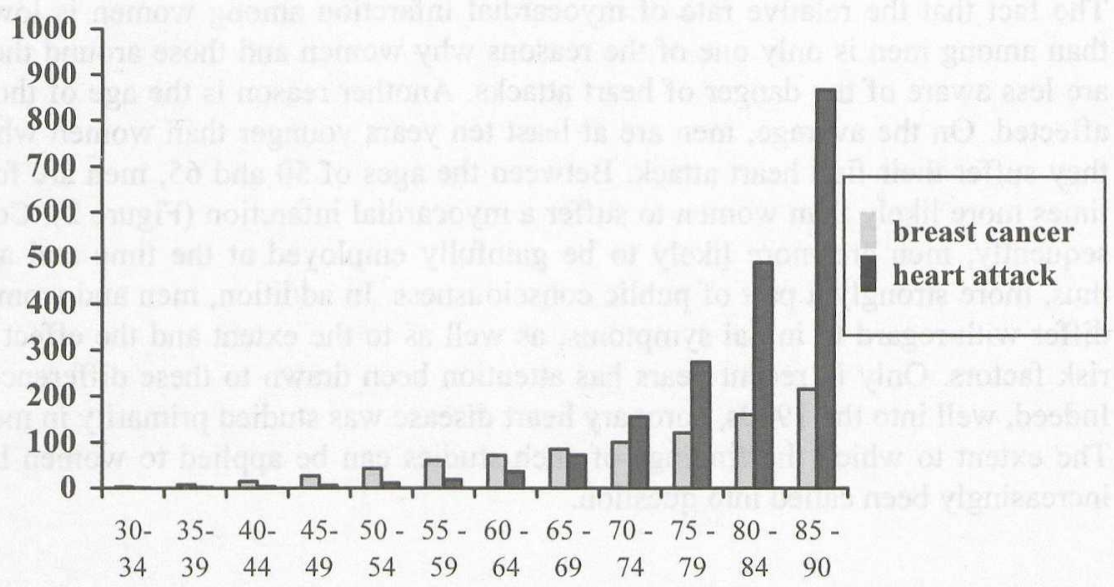


Myocardial infarction has long been viewed as a disease primarily of men; and, indeed, it is true that more men than women in Germany die from heart attacks each year. However, despite the higher prevalence in men, in absolute numbers women actually account for $46 \%$ of all lethal heart attacks in Germany (StBA, 2005 ), and the trend is rising. The relative proportion - calculated per 100,000 population - is somewhat lower due to the longer life expectancy of women (Figure 2).

Figure 2: Acute myocardial infarction according to age and gender per 100,000 population in 2003 (based on information from the StBa, 2005)

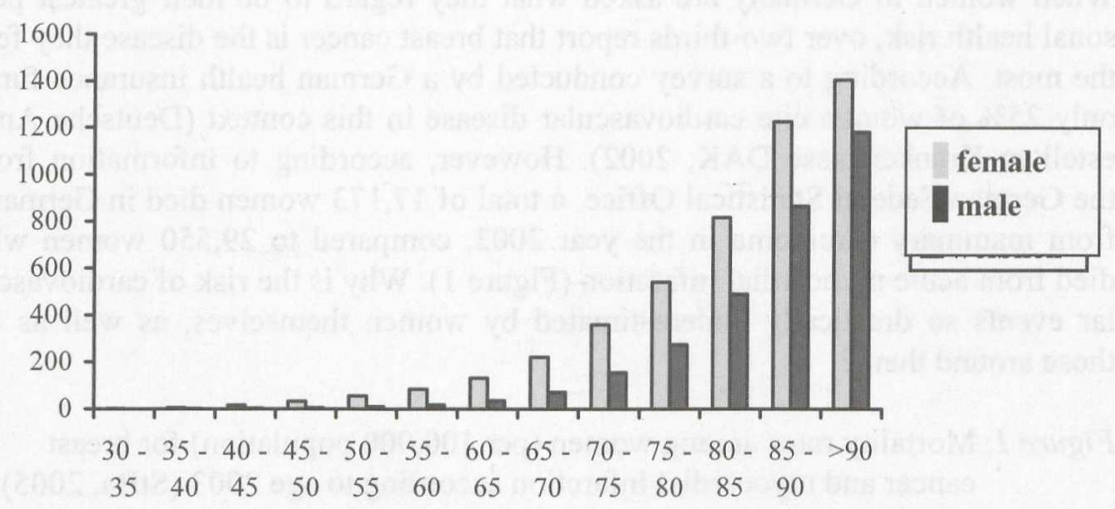

The fact that the relative rate of myocardial infarction among women is lower than among men is only one of the reasons why women and those around them are less aware of the danger of heart attacks. Another reason is the age of those affected. On the average, men are at least ten years younger than women when they suffer their first heart attack. Between the ages of 50 and 65, men are four times more likely than women to suffer a myocardial infarction (Figure 2). Consequently, men are more likely to be gainfully employed at the time and are, thus, more strongly a part of public consciousness. In addition, men and women differ with regard to initial symptoms, as well as to the extent and the effect of risk factors. Only in recent years has attention been drawn to these differences. Indeed, well into the 1990 s, coronary heart disease was studied primarily in men. The extent to which the findings of such studies can be applied to women has increasingly been called into question. 


\section{Developments in Research}

For several decades now, cardiovascular disease has been the leading cause of death in Western industrialised nations. Germany is no exception: cardiovascular diseases - and coronary heart disease (CHD) in particular - are the number one cause of death among both men and women in this country (StBa, 2005). Although it is clear that $\mathrm{CHD}$ does not overwhelmingly affect men, the vast majority of research on CHD in Germany to date has been conducted almost exclusively in male populations (see Mittag, 2002:13). The findings of epidemiological studies have frequently been extrapolated to women, despite the fact that there is a great variety of biological differences between men and women that make such a generalisation highly questionable. It has been known for some time that there are gender-specific differences in risk factor profiles, as well as in symptom manifestation and issues related to starting and managing therapies. Nonetheless, gender differences in cardiovascular risks did not become an important focus of research on an international scale until the early 1990s. This was triggered by an editorial written in 1991 by the then director of the US National Institutes of Health (NIH), Bernadine Healy, in which she criticised the lack of attention paid to women in medical research (Healy, 1991). As part of a larger $\mathrm{NIH}$ initiative, study findings on the aetiology and course of cardiovascular diseases were compiled in 1992, leading to the discovery of a large deficit in research on the situation of female patients (Blumenthal \& Matthews, 1993).

Increasingly, cardiology research in Germany is also taking gender-related factors into account. Several important German studies investigating gender differences in CHD have recently now been published. An important basis for examining coronary risk factors in this country is the MONICA Study (Monitoring Trends and Determinants in Cardiovascular Disease), conducted in the Augsburg region. This project was initiated in the early 1980 s by the World Health Organisation. Its goal was to describe the risk factors for cardiovascular disease in different world regions. The risk factors were determined by means of 3 independent cross-sectional surveys conducted between 1984 and 1995 at 5year intervals on random population samples (see Löwel et al, 2005). This survey is of enormous significance for trend analyses and gender-specific examinations of risk factors. In addition, Schannwell et al (2000) conducted an elaborate gender-comparison study on symptomology and diagnostics in coronary heart disease. Yet another important basis for further research can be found in studies on cardiological rehabilitation. Whereas Grande, Leppin, Mannebach, Romppel \& Altenhöner (2002) and Mittag (2002) focus primarily on the question of whether women are disadvantaged in cardiological rehabilitation programmes, Härtel, Gehring, Klein and Symannek (2003b) examine gender-specific differ- 
ences in the success of rehabilitation measures following patients' first myocardial infarction.

\section{Risk Factors}

A number of risk factors for the development of cardiac diseases have been identified. Data on their prevalence represent an important basis for estimating the relative risk of developing coronary disease. However, there are striking genderand age-related differences in risk factor profiles among individuals. The classical risk factors for cardiac infarction affecting both men and women include cigarette smoking, diabetes, obesity, low high-density lipoprotein (HDL) cholesterol levels, and hypertension. The impact of any particular risk factor can, however, vary according to gender. In addition, there are a variety of risk factors, such as oral contraceptive use, that only affect women. The relative changes in risk factor burden seen in the MONICA study survey clearly show that the risks have increased, especially among women (Löwel et al, 2005). Recently there has been increased discussion about the role played by depression and lack of social support with regard to age and gender in the development of CHD. In contrast, the notion of Type A personality appears to have declined in importance, as can been seen in the comprehensive meta-analysis conducted by Myrtek on the associations between CHD, Type A behaviour, and hostility (Knoll, Scholz, \& Rieckmann, 2005; Myrtek, 2001).

\subsection{Somatic Risk Factors}

Cigarette smoking is the most important single risk factor for the development of coronary heart disease in women and men. In the early 1980 s it was already becoming clear that smoking and oral contraceptive use were the two risk factors in younger female patients $(<50)$ that were tied to issues of social status as well as to those related to family and career planning (Weidemann, Meyer, Fischer, \& Wetzel, 2003). Importantly, whereas the older female patients had begun smoking between the ages of 20 and 30, the younger women had already started between 15 and 18 years of age. Between 1983 and 2003 the number of women smokers steadily increased from $27 \%$ to $30 \%$ among women aged 25 to 69 . In contrast, smoking among men over the same period showed a decline from $42 \%$ to $38 \%$. In the year 2003 , a total of $34 \%$ of women in the $18-29$ years age group were classified as daily smokers (men: 39\%) (Lampert \& Burger, 2004). The increase in smoking prevalence among women has been attributed in particular 
to changes in gender roles; today, for example, smoking is no longer viewed as "unfeminine" (see Waldron, 2002). Studies conducted in the 1980s also show that smoking among women is often associated with emotional stress, whether this be related to work or other psychosocial burdens (Weidemann et al, 2003). As a risk factor for $\mathrm{CHD}$, smoking appears to be particularly harmful to women. In one study, current female smokers had a relative risk for myocardial infarction of 2.24 compared with non-smokers; for male smokers, however, the relative risk was 1.43 (Prescott, Hippe, \& Schnohr, 1998:1043). Furthermore, the younger women are when they begin smoking, the greater their risk. Female smokers who use oral contraceptives and started smoking before the age of 15 are 13 times more likely to develop CHD (Hennekens, Evans, \& Peto, 1989). In addition, active smoking is associated with a drastic reduction in the age of onset for first myocardial infarction: in one study, the average age reduction was 19 years for women (from 79 to 60 years of age) and 7 years for men (from 71 to 64). This means that women who are heavy smokers have their first myocardial infarction an average even of 4 years earlier than male smokers (Hansen, Andersen, \& von Eyben, 1993).

Smoking plays a less important role in the cardiovascular risk profile of older women, which is characterised instead by a combination of hypertension, overweight, and diabetes (Weidemann et al, 2003:56). The prevalence of hypertension in both men and women increases steadily with advancing age. Until the age of 60 , the prevalence of hypertension is higher in men than in women, but the gender gap closes in older age groups. For example, in the 70-79 years age group, approximately $70 \%$ of men and women are affected. From an epidemiological standpoint, a rise in blood pressure is a consequence of aging; this is in contrast to the increase in LDL cholesterol and decrease in HDL cholesterol levels seen in older women, for which the association with menopause has been confirmed (Härtel, 2003a:29).

In her analysis of data from the German Federal Health Survey [Bundesgesundheitssurvey] from 1998, Härtel (2003a:31) shows that women in the youngest age group and women aged 50 years or older demonstrated a higher prevalence of hypercholesterolemia than did men. The greatest differences could be seen in the $60-69$ year age group: $65 \%$ of the women and $44 \%$ of the men in this population suffered from hypercholesterolemia. Only in women 70 years of age or older did the prevalence decrease, thus narrowing the gender gap to some extent. A comparison of these objective figures with self-assessments by survey participants shows that individuals of both genders greatly underestimated their cholesterol levels. However, the false self-assessment among women over the age of 50 is particularly striking. 
Diabetes is another risk factor that has more serious implications for women than for men in the context of CHD. It appears that younger women lose the protection normally afforded by estrogen if they develop diabetes (Härtel, 2003a:26). Indeed, diabetes increases the risk of myocardial infarction by 6-fold in women, and 4-fold in men (Löwel et al, 1999). Diabetes also increases premature mortality after a heart attack by $18 \%$ for women, but only $9.9 \%$ for men (Löwel, Koenig, Engel, Hormann, \& Keil, 2000).

In summary, it is clear that known risk factors for cardiovascular disease in men also apply to women. However, comparing the prevalence of risk factors in women and men is of limited value only. With regard to several risk factors especially smoking and diabetes - the relative risk of suffering a myocardial infarction differs markedly between men and women, as well as between different age groups. Both smoking and diabetes represent a considerably higher coronary risk for women than for men. Because of the increase in smoking among young women in particular, the prevalence of CHD in intermediate age groups is likely to rise as well. The MONICA Index in Augsburg, Germany appears to confirm this supposition: whereas in men the number of myocardial infarctions decreased by $2.3 \%$ per year between 1985 and 1995, it only decreased by $0.7 \%$ per year in women. Furthermore, this decrease was not distributed evenly across the different age groups: whereas women between the ages of 55 and 74 showed a reduction of $2 \%$ per year, younger women (aged 25-54) actually showed an annual increase of $3.8 \%$ (Verbundprojekt zur gesundheitlichen Situation von Frauen in Deutschland, 2001:120). This trend in younger women runs contrary to the general tendency towards a decrease in myocardial infarctions and thus deserves special attention.

\subsection{Psychosocial Risk Factors}

Over the past several years, a growing body of evidence has made clear that not only somatic, but also psychosocial risk factors play a role in the development and clinical manifestation of coronary heart disease. Of course, it should not be forgotten that psychosocial and biological factors often influence each other in a reciprocal manner, and that somatic risk factors such as smoking, overweight, or hypercholesterolemia are often the result of lifestyle behaviours developed in response to stressful life events.

Traditionally, gender research in medicine has focused on the health consequences of the double burden faced by women as they strive to find a balance between career and household work (Mittag, 2002:18). However, the notion that this double burden increases the risk of coronary heart disease has not always 
been confirmed by the available data. Paid work and career building have a number of positive effects that can protect against other harmful factors - including, most notably, economic and social independence, greater social support, and more emotional and intellectual stimulation (Sieverding, 1995). The converse is true, however, when the stress caused by women's double burden comes to outweigh the positive aspects of paid work. Above all, it is women with a low socioeconomic status who experience the greatest burden in this regard: compared to female college graduates, women in unskilled positions are at a far greater risk of developing CHD (Wamala, Mittleman, Horsten, Schenck-Gustafsson, \& OrthGomer, 2000). For both men and women, low socioeconomic status is associated with lifestyle behaviours that increase one's susceptibility to cardiac disease: heavy smoking, increased stress, unhealthy eating habits, and physical inactivity (Brezinka \& Kittel, 1996). However, socioeconomic status appears to have a stronger effect on women than it does on men.

A lack of social support has also been frequently cited as a risk factor for CHD. However, in order to clarify this term, it is important in gender research to draw a distinction between the qualitative and quantitative aspects of social networks. For example, men and women differ with regard to the size of their networks: women tend to have large social networks, whereas men often depend on fewer social contacts. At the same time, men profit more from the support provided by women than vice versa. This is particularly true of middle-aged men. Older individuals can often compensate for the lack of a partner by means of a well-functioning social network. Cardiac events occur more frequently in individuals who are socially isolated and have little social support. This effect is stronger in men than in women (Schwarzer \& Rieckmann, 2002:195). On the other hand, a spouse is frequently the person who is able to call for help when his or her partner is experiencing an acute heart attack. Because women in older age groups have a higher risk of myocardial infarction than their younger counterparts (see Figure 2), it is more likely that they no longer have a partner and are living alone. The lack of a close companion who can call for medical assistance in the event of an emergency may thus have a particularly unfavourable effect on the recognition and treatment of myocardial infarction in older women.

Chronic stress has been cited frequently as a behavioural, and thus modifiable, risk factor in men and women alike. However, in contrast to the most frequently investigated somatic risk factors, elucidating the exact role played by stress in myocardial infarction has been difficult. This may be due to the fact that insufficient attention has been paid to the affective manifestations of chronic emotional distress, such as feelings of "burn out", exhaustion, or pessimism about the future - all of which can contribute to depression or depressive moods (Ladwig, Erazo, \& Rugulies, 2004). Individuals with coronary heart disease 
often have concomitant depression. Frequently, depressive moods are prodromal to an infarction, although it is not always possible to diagnose these in an objective manner. Such "premanifest" illness behaviour, characterised by energy loss and exhaustion, may be relatively non-specific. The question as to whether these factors independently influence the course of disease is still largely unexplored (Ladwig et al, 2004:11). Depression is associated with a number of behavioural risk factors, such as smoking, alcohol abuse, and physical inactivity. On a physiological level, these behaviours correspond, for example, with overweight, diabetes, and hypertension.

\section{Diagnosis and Prognosis After Cardiac Events}

In the sections above we described how individual risk factors affect cardiovascular health. But how do men and women differ with regard to disease manifestation and outcome after myocardial infarction and bypass surgery?

\subsection{Manifestation and Acute Care of Myocardial Infarction}

An elaborate study by Schannwell and colleagues (2000) recorded and analysed clinical symptoms and history in more than 5000 patients (50\% women) who had been admitted to hospital due to suspected CHD. The findings of this study clearly underline the problems involved in diagnosing CHD in women versus men: almost $60 \%$ of the women in the study indicated experiencing atypical anginal symptoms compared to $19 \%$ of the men. This may very well be one of the main reasons why $\mathrm{CHD}$ is underestimated among women in clinical practice. This finding is in accordance with the fact that women were much more likely to visit a general or non-medical practitioner prior to hospital admission (Table 1). In fact, $68 \%$ of women vs. $4 \%$ of men in whom CHD was eventually diagnosed indicated that they had visited at least two medical specialists before being admitted to hospital for an invasive investigation. Interestingly, there were also differences in the type of specialists that had been consulted: only half as many women as men consulted a cardiologist (see Table 1). These factors undoubtedly contributed to the delay in the diagnosis of CHD in women. The average length of time between the onset of clinical symptoms and the actual diagnosis was a startling 77 months for women vs. 9 months for men. One can only speculate on the extent to which the cardiac function of these patients may have deteriorated during this period of time and what consequences this might have for their prog- 
nosis. The delay in diagnosis also translates into considerably higher health care costs.

Table 1: Epidemiological data on prehospital diagnosis of CHD (Schannwell et al, 2000)

\begin{tabular}{|l|c|c|}
\hline & Women with CHD & Men with CHD \\
\hline Age at time of diagnosis & $67 \pm 4.1$ & $57 \pm 2.3$ \\
\hline $\begin{array}{l}\text { Number of months with prior } \\
\text { angina pectoris }\end{array}$ & $77 \pm 8$ & $9 \pm 2$ \\
\hline Prehospital diagnosis & & \\
\hline $\begin{array}{l}\text { General practitioner } \\
(, \text { Praktischer Arzt") }\end{array}$ & $65 \%$ & $43 \%$ \\
\hline & & \\
\hline Internist & $22 \%$ & $57 \%$ \\
\hline Non-medical practitioner & $13 \%$ & $0 \%$ \\
\hline Number of specialists & $11 \%$ & $73 \%$ \\
\hline & $68 \%$ & $4 \%$ \\
\hline & & $82 \%$ \\
\hline Type of specialists & $41 \%$ & $47 \%$ \\
\hline Cardiologist & $83 \%$ & $19 \%$ \\
\hline Orthopaedist & $42 \%$ & $15 \%$ \\
\hline Neurologist & $31 \%$ & \\
\hline Psychotherapist & & \\
\hline
\end{tabular}

Because the manifestations of infarction in women are more complex, and because many women are unaware that they are at risk, there is also a long delay between symptom onset and eventual diagnosis in cases of acute myocardial infarction. Men who experience severe chest pain are probably more likely to suspect a heart attack and seek medical help, either of their own accord or at the prompting of someone else. Women, in contrast, may possibly wait longer before seeking assistance (Mittag, 2002:65). Myocardial infarction is still regarded as a "man's disease", especially by younger women and those around them. The prodromal symptoms of acute myocardial infarction are often non-specific in women. Women are more likely than men to have symptoms that differ from those of typical angina pectoris, experiencing, for example, only shortness of breath, nausea, sweating, or neck pain. This difference in the premonitory manifestation of infarction may be one of the reasons for the higher mortality rate in 
women following a heart attack. Not only women themselves, but also their attending physicians, often appear to be interpreting their symptoms incorrectly, leading to delayed hospital admission. In women, the symptoms of an impending infaretion are more likely to be attributed at first to spinal disorders or gastric complaints (Härtel, 2003a:47). This is one of the reasons why women reach the emergency room an average of 60 minutes later than men after noticing initial symptoms (Grande et al, 2002:150). Analyses of data from the MONICA Study in Augsburg, Germany, also point to a clear association between marital status and mortality. A total of $39 \%$ of the women vs. $4 \%$ of men in this population who experienced sudden death after acute myocardial infarction were widowed. When women suffer a heart attack, they are more likely to be alone and lacking a partner who would be able to call an ambulance (Mittag, 2002:65). Because the decision to call for medical assistance usually depends on the presence of a friend or relative, it may well be that a number of female heart attack patients die due to delays in treatment (Härtel \& Löwel, 1991). Thus, the fact that women are admitted to hospital later than men should not be interpreted solely as the result of poor quality health care.

\subsection{Prognosis After Myocardial Infarction and Bypass Surgery}

Since the early 1990 s a large number of epidemiological and clinical studies have focused on the question of whether women have an increased risk of premature death after myocardial infarction compared to men. Data from the MONICA Project of the World Health Organisation have shown that this is the case in the majority of the 21 countries that participated in the study (see Härtel, 2003a:14). Men may be more likely than women to suffer heart attacks - but women are more likely to die from them. Data from the Augsburg Index from $1985 / 95$ for individuals between the ages of 25 and 74 show that, of the heart attack victims who died prematurely from the event, $34 \%$ did so before reaching the emergency room. Another $20 \%$ died on their first day in hospital, and another $5 \%$ between the second and twenty-eighth day in hospital. This means that only $41 \%$ of those affected were still alive after 4 weeks (Verbundprojekt zur gesundheitlichen Situation von Frauen in Deutschland, 2001).

The fact that rates of premature death among women changed only minimally from $1985 / 87$ to $1995 / 97$ is surprising considering the frequent claims that the quality of acute treatment in myocardial infarction no longer differs between men and women, as it once did (Härtel, 2003a:15). At first glance, a logical explanation for higher mortality in women would be that they are, on the average, older than men when they experience their first infarction. Whereas in men CHD 
mortality increases in a linear fashion starting at the age of 35 , in women the curve is shifted up by approximately 10 years and shows a strong increase in mortality starting at approximately the age of 65 (see Figure 2). More than 95\% of CHD-related deaths in women occur in this age group. In contrast, only $37 \%$ of CHD-related deaths in men occur in individuals above the age of 65 (Mittag, 2002:11). In addition, women in this age group often suffer from other agerelated diseases and are treated in a less "aggressive" manner. However, a closer look at the available epidemiological data reveals that the older average age of women who present themselves with CHD is not a sufficient explanation for their higher mortality rate. As was demonstrated by Vaccarino, Parsons, Every, Barron and Krumholz (1999) in a prospective cohort study in the United States, younger women showed higher mortality following a heart attack than did older women. Younger women ( $<50$ years of age) in the study were also more than twice as likely to die after a heart attack than age-matched men - a gender gap which did not close until approximately the age of 70 .

Coronary heart disease is often treated with bypass surgery, a method by which a blood vessel taken from the tissues of the chest, arms, or legs is used to route blood around blockages in the coronary arteries. The number of women who undergo this procedure has risen continually in recent years; today women comprise almost $30 \%$ of all bypass patients. However, it should be noted that the increased use of such invasive methods is not always associated with better chances of survival. Women are generally older than men at the time of diagnosis, and their treatment is made more difficult by the fact that their coronary system differs from that of men in a variety of respects. As a result, less "aggressive" treatment in women is not necessarily a sign of disadvantage, but rather is based on the fact that women who are diagnosed as suffering from coronary disease are older and have a different clinical picture than men. The role played by the expectations and gender-specific stereotypes of physicians has yet to be determined.

There is a general consensus that women have a poorer prognosis than men following bypass surgery (Regitz-Zagrosek et al, 2004; Vaccarino et al, 2003). The only German study on this topic to date examined in-hospital mortality of 17,528 consecutive inpatients who underwent coronary artery bypass grafting between 1992-2001 at the German Heart Institute in Berlin (Regitz-Zagrosek et al, 2004). Compared to men, women in the study had a 1.5 -fold higher risk of death following the bypass operation. This increased risk was not evenly distributed among the different age groups, however. Whereas women who were under 50 had a 2.4-fold higher risk, the gender gap closed with advancing age; at approximately the age of 70 , men and women showed a comparable risk of mortality (Figure 5). 
Figure 3: Mortality risk ratio according to age group in women vs. men after bypass surgery (Regitz-Zagrosek et al, 2004)

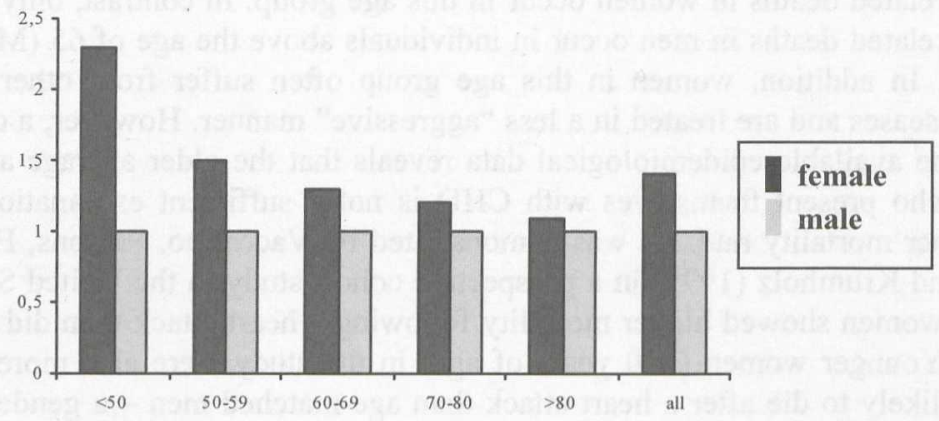

This does not appear consistent with the observation that premenopausal woman are protected from coronary heart disease. It is conceivable that women who undergo bypass surgery at a relatively young age comprise a special risk group.

Women have a poorer prognosis than men, both following myocardial infarction and after bypass surgery. In both of these contexts, it is especially younger women who have a markedly higher risk of mortality compared to men (Regitz-Zagrosek et al, 2004; Vaccarino et al, 1999). Currently known risk factors cannot fully explain this gender difference, however. As a result, one can only speculate on the age and gender interactions observed in the abovementioned studies. Clinical parameters that have been suggested in this context include genetic risk profiles and hormone status (Regitz-Zagrosek et al, 2004). Depression has also been identified in a number of studies as a predictor of mortality following coronary artery bypass surgery (Blumenthal et al, 2003) and after myocardial infarction (Frasure-Smith, Lesperance, Juneau, Talajic, \& Bourassa, 1999). Because women in Germany are almost twice as likely to suffer from depression as men (Brüggemann \& Haltenhof, 2002), this may prove to be an explanatory approach to higher mortality rates in women.

Another reason for the poorer prognosis for women with CHD may be due to an inability to reduce the number of household activities they perform, giving them less opportunity to recover after myocardial infarction or bypass surgery. Several studies in the United States have examined the association between household activities and health status after cardiac events. In a prospective longitudinal study (15 men, 15 women), Rose, Suls and Green (1996) showed that the spouses of female patients assumed greater responsibility for domestic tasks in 
the first weeks after the heart attack. As early as 10 weeks after the heart attack, however, the female patients were already performing substantially more domestic work than their spouses. The support provided by male spouses was thus limited primarily to the time directly following discharge from hospital. In contrast, men were able to markedly reduce the number of household activities they performed following myocardial infarction, allowing for a longer recovery period. In general, it appeared to be difficult for patients to forgo traditional sextyped activities. In a later American longitudinal study with 63 patients, the correlations between the symptoms reported and activities performed were quite variable with respect to gender. In men, there was a reverse correlation: the more symptoms they reported, the more they limited their household activities. In contrast, female patients appeared to pay little or no heed to their symptoms (Lemos, Suls, Jenson, Lounsbury, \& Gordon, 2003:13). Despite their functional limitations and more severe symptoms, women continued to perform their usual activities and appeared to pay less attention to their own needs. This pattern of behaviour may place female patients at particular risk, especially considering the fact that household activities are often not distributed evenly throughout the day, but rather are concentrated within a certain period of time (Jenson, Suls, \& Lemos, 2003). In the early postoperative phase, when patients are instructed to avoid physical strain - in particular of their upper body - such behaviour undoubtedly represents an increased risk. As far as we know, to date, no studies have been conducted in Germany on the burden of household work in women following myocardial infarction or bypass surgery.

\section{Gender- and Age-Related Aspects of Rehabilitation}

In Germany, approximately 280,000 persons experience a myocardial infarction each year, and hundreds of thousands of patients require bypass surgery or undergo procedures to widen narrowed coronary arteries (StBA, 2003). Acute cardiac events interrupt the everyday working lives of affected individuals and deprive them of their normal social environment. Current cardiac rehabilitation programmes were developed in the 1960s and 1970s with younger men in mind and had the primary goal of helping these individuals return to work. However, with health care resources becoming increasingly scarce, it is today more important than ever to determine precisely which measures are needed most, and to evaluate the effectiveness of these measures, in an evidence-based fashion. 


\subsection{Are Women Disadvantaged With Regard to Health Care?}

In 1991 the Rehabilitation Commission of the German Association of Pension Funds [Verband Deutscher Rentenversicherungsträger, VDR] presented a series of recommendations on the further development of medical rehabilitation in Germany. In its report, the Commission noted that rehabilitation services for several diagnoses were still utilised much less frequently by women than men in this country (VDR/Reha-Kommission, 1992:187). A little over a decade later, however, the situation has changed. None of the three recent rehabilitation studies (Grande et al, 2002, Mittag, 2002, Härtel et al, 2003b) focusing on gender discrepancies was able to find any evidence that women were disadvantaged in a quantitative manner with regard to access to services or service utilisation. However, this does not answer the question as to the appropriateness of particular services. When they begin rehabilitation programmes, women are considerably more impaired physically and psychologically than comparably aged men. This applies to disease severity, exercise tolerance, comorbidity, risk factors, and health-related quality of life. In women, anxiety and depressive symptoms appear to be especially pronounced at the start of rehabilitative therapy compared to men - a difference that could also be clearly seen at the end of rehabilitation in at least one German study on the topic (Härtel, 2005:11). In the rehabilitation study by Mittag (2002:68), younger women, in particular, experienced depression as a result of their illness. They more frequently reported feeling that their personal health was dependent on chance or fate, seeing as a result fewer opportunities to influence the state of their health through treatment or, for example, a change in lifestyle. At the same time, younger women suffered considerably more disease-related worries compared with men or, in particular, older women. Younger women also reported experiencing pronounced vital exhaustion (Mittag, 2002:68). This can be explained by the personal circumstances of many younger women, for whom family- and work-related stress often represent an especially large burden. Moreover, the disease often appears in a completely unexpected manner at this time of life and requires a great deal of adjustment. And in the study by Mittag (2002:68) it is precisely the younger women who described their situation as unclear, difficult to manage, or unsatisfying. According to traditional concepts of the family, women are assigned the expressive role - that is, they are responsible for providing their husbands and children with socioemotional support. The lack of control over one's own life can set in motion a vicious circle that eventually leads to severe depression (e.g. NolenHoeksema, Larson \& Grayson, 1999:1061).

Differences in personal circumstances also appear to influence the reasons reported by men and women for not participating in outpatient rehabilitation 
programmes, such as in supervised exercise groups. Women most often give practical reasons for non-participation, citing for example that the programme is too far from their home or that they have no means of transportation. The main reasons for non-participation cited by men include lack of interest or the opinion that the programme is "not fun" (Härtel, 2003a:51). Because of this, Härtel et al (2003b:45) recommends therapy programmes that take the special circumstances of women into account. Programmes like these are based on separate, womenonly groups that deal specifically with the multiple comorbidities common to women, that teach self-confidence, and that provide instructions on how to make use of what they have learned in everyday life. The emphasis lies on the psychosocial and familial burdens, fears, and depressions typically experienced by women. To date, such programmes have met with strong approval by female patients (Härtel, 2005:12). It may be that new social structures are able to develop in women's groups like these, leading to greater mutual support.

\subsection{The Role of Age in the Allocation of Health Care Services}

According to the findings of the three rehabilitation studies described above, gender does not have an effect on the allocation of health care services among patients with CHD. A patient's age, however, does appear to play an important role in this regard (Grande et al, 2002:151). Grande et al assert that younger patients receive a larger number of diagnostic interventions, such as exercise ECG testing and coronary angiography. In addition, there were clear age-related differences with regard to discharge medication and patients' use of rehabilitation services. Participants in rehabilitation programmes and supervised exercise groups were an average of 3 to 4 years younger than non-participants. The older the patients were, the less they made use of services such as bicycle ergometer training, psychological counselling, and/or anti-smoking classes (Grande et al, 2002:151). These differences are not a sign that care was being tailored to the needs of certain groups of individuals, however, because older patients simply received fewer, rather than different, services (Grande et al, 2002:157). These findings show that some of the differences, which at first glance appear to be based on gender, are in reality due to age. Indeed, age appears to be a more important factor than gender with regard to the allocation of health care services (Grande et al, 2002:151). Focusing too narrowly on gender can easily obscure this fact by confounding the pre-existing sociodemographic and medical characteristics that lead a patient to make use of, or receive, particular health care services. In the acute care phase of treatment, the greater prevalence of multimorbidity, the less favourable risk factor profile, and the poorer state of health in 
older patients undoubtedly play an important role. Furthermore, during the rehabilitation phase - if not much earlier - patients themselves also influence the type of care they receive insofar as they consent to, or decline, certain services. Differences in patients' subjective perception of disease, which have been found in a number of studies, may exert a substantial influence in this context (Grande et al, 2002:154). Because the number of older patients in rehabilitation care is expected to rise considerably in the future, it is essential that new rehabilitation services be developed that are tailored specifically to the needs of this particular age group (Grande et al, 2002:154).

\section{Conclusions}

The differences in CHD rates between men and women begin to level out as patients grow older. Due to the aging of society and changes in the risk factor profiles of younger women, it is very likely that the number of female heart patients will increase dramatically in the future. The findings of recent risk factor analyses underscore the importance of differentiating patients according to gender and age in medical research and treatment. Indeed, there are clearly risk factors, such as smoking, that exert a greater influence on the incidence of coronary heart disease in women than in men, and that interact with other risk factors in different ways or to a different extent depending on gender. Gender-specific factors also influence the manifestation, course, and prognosis of cardiovascular diseases. In contrast, age appears to be the major determinant in the allocation of health care services. Whereas men and women, in general, receive comparable health care services, older patients receive fewer services than younger patients, regardless of their gender. The reasons for these differences and the roles played by patients and physicians cannot be fully explained based on the available data. However, the overarching goal of achieving "fairness" or "equality" in health care cannot be reached by completely standardising the services provided. Standardisation carries with it the danger of neglecting the unique characteristics and needs of certain groups. Studies have repeatedly shown that the positive effects of rehabilitation programmes are difficult to sustain (Willich et al, 2001). In order to account for changes in lifestyles and health-related behaviour, it will be necessary to develop new concepts that differentiate patients according to gender and age.

Younger female patients appear to comprise a special risk group. To date, few studies in Germany have focused explicitly on the role played by gender in coronary heart disease. Almost no research has been conducted in this country on the extent to which family- and work-related stress influences CHD, patient 
recovery following myocardial infarction, or bypass surgery. It is difficult to generalise the findings of studies from America or Scandinavia, for example, because of sociocultural differences. As a result, new studies in Germany that focus on these issues are urgently needed. In Europe, the first "Institute of Gender Related Medicine" was founded in Sweden in 2001 at the Karolinska Institute. The first such institution in Germany, the Centre for Gender in Medicine [Zentrum für Geschlechterforschung in der Medizin, GiM], was established in 2004 at the Charité University Medical Centre in Berlin. The task of the GiM is to investigate why the prevalence, course, and manifestation of many diseases differ between women and men. The example of gender- and age-related effects in cardiovascular disease makes clear that gender research in medicine is, by definition, an interdisciplinary field. In which cases do the effects of age contribute more than the effects of gender to our understanding of variance? To what extent can different examples of variance in medicine be traced back to biological factors, or to social ones? In the English-speaking countries, "gender" has become an established concept and is used to distinguish between the social and cultural characteristics of men and women and their biological sex (see Legato, 2004). Societies assign different roles and allocate different resources to men and women, and they judge their contributions to the community according to different standards, as well. How much of what we describe as "masculine" or "feminine" can be attributed to biological sex and thus cannot be influenced? And how much is acquired and thus subject to change? The process of investigation and discovery in this field of inquiry has been set in motion, but there are many important questions that still need to be answered.

\section{References}

Blumenthal, J. A., Lett, H. S., Babyak, M. A., White, W., Smith, P. K., Mark, D. B., Jones, R., Matthew, J. P., \& Newman, M. F. (2003). Depression as a risk factor for mortality after coronary artery bypass surgery. The Lancet, 362, 604-609.

Blumenthal, S. J., \& Matthews, K. A. (1993). Psychosocial aspects of cardiovascular disease in women: Introduction and overview. Annals of Behavioral Medicine, 15 (2-3), 109-111.

Brezinka, V., \& Kittel, F. (1996). Psychosocial factors of coronary heart disease in women: a review. Social Science \& Medicine, 42, 1351-1365.

Brüggemann, B., \& Haltenhof, H. (2002). Der Beitrag soziokultureller Faktoren zum Verständnis der Geschlechterverteilung depressiver Störungen. Zeitschrift für Klinische Psychologie, Psychotherapie und Psychiatrie, 101-132.

Deutsche Angestellten Krankenkasse, DAK (2002). "Was wissen Frauen über den Herzinfarkt?"Emnid/DAK. 
Frasure-Smith, N., Lesperance, F., Juneau, M., Talajic, M., \& Bourassa, M. G. (1999). Gender, depression, and one-year prognosis after myocardial infarction. Psychosomatic Medicine, 61, 26-37.

Grande, G., Leppin, A., Mannebach, H., Romppel, M., \& Altenhöner, T. H. (2002). Geschlechtsspezifische Unterschiede in der kardiologischen Rehabilitation: Abschlussbericht Universität Bielefeld.

Hansen, E. F., Andersen, L. T., \& von Eyben, F. E. (1993). Cigarette smoking and age at first acute myocardial infarction and influence of gender and extent of smoking. American Journal of Cardiology, 71, 1439-1442.

Härtel, U. (2003a). Ist-Analyse Prävalenz der Herz-Kreislauferkrankungen bei Frauen in NRW. Gutachten im Auftrag der Enquete-Kommission "Zukunft einer frauengerechten Gesundheitsversorgung in NRW. Düsseldorf. URL: http://www.landtag.nrw.de/ portal/WWW/GB_I/I.1/EK/EKALT/13 EK2/aktuelles.jsp.

Härtel, U., Gehring, J., Klein, G., \& Symannek, C. (2003b). Untersuchung geschlechtsspezifischer, biomedizinischer und psychosozialer Einflüsse auf den langfristigen Erfolg von Reha-Maßnahmen bei Patienten mit koronarer Herzkrankheit: Abschlussbericht (1. Förderphase) BMBF Bericht.

Härtel, U. (2005). Geschlechtsspezifische Unterschiede in der kardiologischen Rehabilitation. informiert! Nr.9.

Härtel, U., \& Löwel, H. (1991). Familienstand und Überleben nach Herzinfarkt. Ergebnisse des Augsburger Herzinfarktregisters. Münchner Medizinische Wochenschrift, 133, 464-468.

Healy, B. (1991). The Yentl syndrome. The New England Journal of Medicine(325).

Hennekens, C., Evans, D., \& Peto, R. (1989). Oral contraceptive use, cigarette smoking and myocardial infarction. British Journal of Family Planning, 5, 66-67.

Jenson, M., Suls, J., \& Lemos, K. (2003). A comparison of physical activity in men and women with cardiac disease: do gender roles complicate recovery? Women and Health, 37(1), 31-47.

Knoll, N., Scholz, U., \& Rieckmann, N. (2005). Einführung in die Gesundheitspsychologie. München: Ernst Reinhardt Verlag/UTB.

Ladwig, K.-H., Erazo, N., \& Rugulies, R. (2004). Depression, Angst und Vitale Erschöpfung vor Ausbruch der koronaren Herzkrankheit. Frankfurt a.M.:VAS

Lampert, T., \& Burger, M. (2004). Rauchgewohnheiten in Deutschland - Ergebnisse des telefonischen Bundes-Gesundheitssurveys 2003. Das Gesundheitswesen, 66, 511-517.

Legato, M. (Ed.). (2004). Principles of Gender-Specific Medicine. Amsterdam: Academic Press

Lemos, K., Suls, J., Jenson, M., Lounsbury, P., \& Gordon, E. E. I. (2003). How do female and male cardiac patients and their spouses share responsibilities after discharge from the hospital? Annals of Behavioral Medicine, 25, 8-15.

Löwel, H., Döring, A., Schneider, A., Heier, M., Thorand, B., \& Meisinger, C. (2005). The MONICA Augsburg Surveys - Basis for Prospective Cohort Studies. Gesundheitswesen, 67 Sonderheft 1, S13-S18.

Löwel, H., Koenig, W., Engel, S., Hormann, A., \& Keil, U. (2000). The impact of diabetes mellitus on survival after myocardial infarction: can it be modified by drug treatment? Result of a population-based myocardial infarction register follow-up study. Diabetologia, 43, 218-226. 
Löwel, H., Stieber, J., Koenig, W., Thorand, B., Hörmann, A., Gostomzyk, J., \& Keil, U. (1999). Das Diabetes-bedingte Herzinfarktrisiko in einer süddeutschen Bevölkerung. Ergebnisse der MONICA-Augsburg Studien 1985-1995. Diabetes und Stoffwechsel, $8,11-21$.

Mittag, O. (2002). Vergleich der Verläufe nach erstem Herzinfarkt bzw. ACVB-Opration oder PTCA bei Frauen und Männern:B-1 Projekt im Norddeutschen Forschungsverbund. Abschlussbericht 1. Förderphase.

Myrtek, M. (2001). Meta-analyses of prospective studies on coronary heart disease, type A personality, and hostility. International Journal of Cardiology, 79, 245-251.

Nolen-Hoeksema, S., Larson., J., \& Grayson, C. (1999). Explaining the gender difference in depressive symptoms. Journal of Personality and Social Psychology, 77, 5,10611072.

Prescott, E., Hippe, M., \& Schnohr, P. (1998). Smoking and risk of myocardial infarction in women and men: Longitudinal population study. British Medical Journal, 316, 1043-1047.

Regitz-Zagrosek, V., Lehmkuhl, E., Hocher, B., Goesmann, D., Lehmkuhl, H. B., Hausmann, H., \& Hetzer, R. (2004). Gender as a risk factor in young, not in old, women undergoing coronary artery bypass grafting. Journal American College of Cardiology, 44 (11), 2413-2414.

Rose, G. L., Suls, J., \& Green, P. J. (1996). Comparison of adjustment, activity, and tangible social support in men and women patients and their spouses during the six months post-myocardial infarction. Annals Of Behavioral Medicine, 18, 264-272.

Schannwell, C. M., Schoebel, F. C., Lazica, D., Marx, R., Plehn, G., Leschke, M., \& Strauer, B. E. (2000). Besonderheiten der koronaren Herzkrankheit in der klinischen Symptomatik und Erstdiagnostik bei Frauen. Deutsche Medizinische Wochenschrift, $125,1417-1423$.

Schwarzer, R., \& Rieckmann, N. (2002). Social Support, Cardiovascular Disease, and Mortality. In G. Weidner \& M. S. Kopp \& M. Kristenson (Eds.), Heart Disease: Environment, Stress and Gender (pp. 185-194). Amsterdam: IOS Press.

Sieverding, M. (1995). Die Gesundheit von Müttern - Ein Forschungsüberblick. Zeitschrift für Medizinische Psychologie, 4, 6-16.

StBA. (2005). Gesundheitswesen. Todesursachen in Deutschland 2003.Wiesbaden: Statistisches Bundesamt.

Vaccarino, V., Lin, Z. Q., Kasl, S. V., Mattera, J. A., Roumanis, S. A., Abramson, J. L. \& Krumholz, H. M. (2003). Gender differences in recovery after coronary artery bypass surgery. Journal of the American College of Cardiology, 41, 307-314.

Vaccarino, V., Parsons, L., Every, N. R., Barron, H. V., \& Krumholz, H. M. (1999). Sexbased differences in early mortality after myocardial infarction. New England Journal of Medicine, 341, 217-225.

VDR/Reha-Kommision (Ed.). (1992). Bericht der Reha-Kommission des Verbandes Deutscher Rentenversicherungsträger. Empfehlungen zur Weiterentwicklung der medizinischen Rehabilitation in der gesetzlichen Rentenversicherung. Frankfurt am Main:VDR. 
Verbundprojekt zur gesundheitlichen Situation von Frauen in Deutschland (2001). Bericht zur gesundheitlichen Situation von Frauen in Deutschland (Schriftenreihe des Bundesministeriums für Familie, Senioren, Frauen und Jugend, Band 209). Stuttgart: Kohlhammer.

Waldron, I. (2002). Trends in gender differences in coronary heart disease mortalityrelationships to trends in health-related behavior and changing gender roles. In G. Weidner, M. S. Kopp \& M. Kristenson (Eds), Heart Disease: Environment, Stress and Gender. Amsterdam: IOS Press, 80-98.

Wamala, S. P., Mittleman, M. A., Horsten, M., Schenck-Gustafsson, K., \& Orth-Gomer, K. (2000). Job stress and the occupational gradient in coronary heart disease risk in women. The Stockholm Female Coronary Risk Study. Social Science \& Medicine, $51,481-489$.

Weidemann, H., Meyer, K., Fischer, T., \& Wetzel, A. (2003). Frauen und koronare Herzkrankheit. Altersverteilung, Rauchen und orale Kontrazeption, klassische Risikofaktoren, psychosoziale Konstellationen, körperliches Training. Frankfurt a.M.:VAS

Willich, S.N., Müller-Nordhorn, J., Kulig, M., Binting, S., Gohlke, H., Hahmann, H., Bestehorn, K., Krobot, K. \& Völler, H. (2001). Cardiac risk factors, medication and recurrent clinical events after acute coronary disease - a prospective cohort study. European Heart Journal, 22, 307-313. 